\title{
Efektifitas Cognitive Behaviour Therapy di Sekolah: Meta Analisis Review
}

\author{
Richma Hidayati ${ }^{1,2^{*}}$, Nur Hidayah ${ }^{2}$, M. Ramli ${ }^{2}$, Imam Hambali ${ }^{2}$, Triyono ${ }^{2}$. \\ 1 Universitas Muria Kudus, Indonesia. \\ ${ }^{2}$ Universitas Negeri Malang, Indonesia. \\ *Korespondensi: richma.hidayati@umk.ac.id
}

\begin{abstract}
Cognitive behavioral therapy (CBT) is a popular therapy that is applied to various problems. The purpose of this study is to provide a survey approved by a meta-analysis supported by CBT. This study reviews 10 meta-analytic studies and discusses CBT in students in schools for the following problems, namely: Anxiety, Emotion, Self-Confidence, Self-Efficacy, and CBT Based on Local Wisdom. Additional analytical meta review to address CBT problems for various problems in school children. The strongest support for $C B T$ is from monitoring and transition. CBT showed a higher response rate and was widely considered in these 7 reviews and only three reviews reported that $C B T$ had a lower response rate in care. In general, the CBT evidence base is very strong. However, additional research is needed to study the efficacy of CBT for randomized controlled studies. In addition, using CBT in schools depends on the level of education and age of children.
\end{abstract}

Keywords: Meta-analisis Review; Cognitive Behavior Therapy; School Students.

How To Cite: Hidayati, R., Hidayah, N., Ramli, M., Hambali, I., \& Triyono. (2020) Efektifitas Cognitive Behaviour Therapy di Sekolah: Meta Analisis Review. Biblio Couns: Jurnal Kajian Konseling dan Pendidikan, 3(1), 31-40.

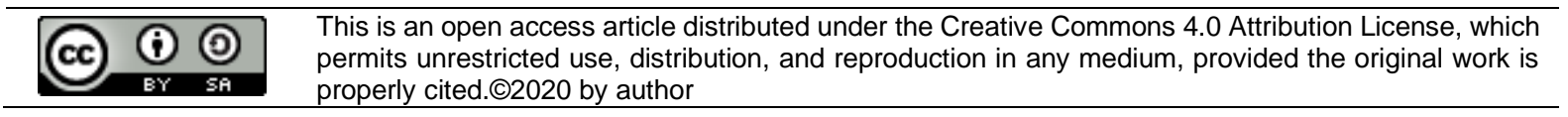

\section{PENDAHULUAN}

Cognitive-behavioral therapy (CBT) mengacu pada kelas intervensi dengan berbagai premis dasar bahwa gangguan mental dan tekanan psikologis dipertahankan oleh faktor kognitif. Premis inti dari pendekatan perawatan ini, seperti yang dipelopori oleh Beck (Anastopoulos \& King, 2015; Cully \& Teten, 2008; SAMHSA et al., 2006) dan Ellis (Fitzgerald, 2013), berpendapat bahwa kognisi maladaptif berkontribusi pada pemeliharaan tekanan emosional dan masalah perilaku. Menurut model Beck (Raedt, 2020), kognisi maladaptif ini mencakup kepercayaan umum, atau skema, tentang dunia, diri, dan masa depan, sehingga memunculkan pemikiran spesifik dan otomatis dalam situasi tertentu. Model dasar berpendapat bahwa strategi terapeutik untuk mengubah kognisi maladaptif ini menyebabkan perubahan dalam tekanan emosional dan perilaku bermasalah.

Sejak awal, sejumlah protokol CBT khusus gangguan telah dikembangkan yang secara khusus menangani berbagai faktor pemeliharaan kognitif (Jongerden \& Bögels, 2015)dan perilaku dari berbagai gangguan. Meskipun protokol perawatan khusus-gangguan ini menunjukkan perbedaan besar dalam beberapa teknik perawatan khusus (Asbrand, Heinrichs, Nitschke, Wolf, Schmidtendorf, et al., 2019; Alladin, 2015; Salomonsson et al., 2019), mereka semua memiliki model inti yang sama dan pendekatan umum untuk perawatan.

Konsisten dengan model medis psikiatri, tujuan keseluruhan treatmen CBT adalah pengurangan gejala, peningkatan fungsi, dan remisi gangguan. Untuk mencapai tujuan ini, 
pasien menjadi peserta aktif dalam proses pemecahan masalah kolaboratif untuk menguji dan menantang validitas kognisi maladaptive (Castella et al., 2014; Nosouhian \& Javadi, 2018) dan untuk memodifikasi pola perilaku maladaptif. Dengan demikian, CBT modern mengacu pada intervensi yang menggabungkan berbagai teknik yang berfokus pada kognitif, perilaku, dan emosi (Castella et al., 2014; Essau et al., 2019; Maric et al., 2018). Meskipun strategi ini sangat menekankan faktor kognitif, komponen fisiologis, emosional, dan perilaku (Eiraldi et al., 2018) juga diakui sangat memainkan peranan penting dalam pemeliharaan gangguan tersebut.

Tinjauan baru-baru ini dari meta-analisis CBT mengidentifikasi 16 ulasan kuantitatif yang mencakup 332 uji klinis yang mencakup 16 gangguan atau populasi yang berbeda (Asbrand, Heinrichs, Nitschke, Wolf, \& Tuschen-ca, 2019; Freeman, 2006; Neill et al., 2017; Taylor et al., 2014) Sejauh pengetahuan kami, ini adalah ulasan pertama dari studi metaanalitik yang memeriksa keefektifitasan CBT untuk sejumlah gangguan psikologis. Artikel ini sejak itu menjadi salah satu ulasan CBT yang paling berpengaruh. Namun, strategi pencarian terbatas, karena hanya satu meta-analisis yang dipilih untuk setiap gangguan. Selain itu, pencarian hanya mencakup periode hingga 2004, tetapi banyak ulasan telah diterbitkan sejak itu. Bahkan, sebagian besar penelitian (95\%) diterbitkan setelah 2004. Tujuan dari meta analisis ini adalah untuk menyediakan survei komprehensif dari semua meta-analisis kontemporer yang memeriksa basis bukti untuk kemanjuran CBT hingga saat ini. Metaanalisis yang termasuk dalam ulasan ini semuanya dinilai logis secara metodologi.

\section{METODE}

Untuk mendapatkan artikel untuk ulasan ini, kami mencari di pustaka tandfonline, Springer, elsivier dan pustaka Cochrane menggunakan kata-kata kunci berikut: metaanalisis dan CBT in School, meta-analisis dan terapi kognitif, tinjauan kuantitatif dan CBT , tinjauan kuantitatif CBT. Pencarian awal ini menghasilkan $145 \mathrm{klik}, 13$ di antaranya adalah duplikat dan harus dikecualikan. 678 artikel non-duplikat yang tersisa diperiksa lebih lanjut untuk menentukan apakah mereka memenuhi kriteria inklusi khusus untuk keperluan ulasan ini. Semua penelitian yang dimasukkan harus merupakan tinjauan kuantitatif (mis., Meta-analisis) dari CBT. Untuk membatasi ulasan ini pada studi kontemporer, hanya artikel yang diterbitkan sejak tahun 2013 yang dimasukkan. Sampel akhir yang termasuk dalam ulasan ini terdiri dari 13 meta-analisis.

Meta-analisis dikategorikan ke dalam kelompok-kelompok untuk memberikan pemeriksaan keefitivitasan CBT yang paling bermakna dan luas di berbagai bidang masalah dan populasi penelitian. Pengelompokan utama adalah mengambil data meta analisis keefektivitasan CBT pada Siswa di Sekolah dan dikelompokkan menjadi 4 kelompok utama yaitu: CBT dan Students Anxiety, CBT and Students Emotion, CBT and Students self confidence and Self Efficacy, CBT and Local Wisdom.

\section{HASIL PENELITIAN DAN PEMBAHASAN}

Penelitian meta analisis ini terkelompokkan menjadi empat bagian dengan masingmasing tema tertentu namun tetap dalam ruang lingkup siswa disekolah. Pengelompokan dapat dilihat dalam Table 1. 
Tabel 1. Pengelompokan Meta-Analisis

\begin{tabular}{|c|c|c|c|}
\hline Kelompok & Author & Tahun & Judul \\
\hline \multirow{18}{*}{$\begin{array}{l}\text { CBT and } \\
\text { Students } \\
\text { Anxiety }\end{array}$} & Lotfi, S., Eizadi-fard, & 2011 & Social and The Effect of \\
\hline & R., Ayazi, M., \& Amin, & & Meichenbaum , s \\
\hline & & & Behaviour Modification Therapy on \\
\hline & & & Reduction of Test Anxiety \\
\hline & & & Symptoms in High School Girls. \\
\hline & $\begin{array}{l}\text { Vincent, L., Norton, P. } \\
\text { J., \& Norton, P. J. }\end{array}$ & $\underline{2018}$ & $\begin{array}{l}\text { The effectiveness of Cognitive- } \\
\text { Behavioral Group Therapy on self- } \\
\text { efficacy and assertiveness among } \\
\text { anxious female students of high } \\
\text { schools. }\end{array}$ \\
\hline & Stallard, $\quad$ P., & $\underline{2014}$ & Classroom-based cognitive \\
\hline & Skryabina, E., Taylor, & & behaviour therapy ( FRIENDS ): a \\
\hline & $\begin{array}{ll}\text { G., } & \text { Phillips, } \\
\text { Daniels, } & \text { H., }\end{array}$ & & Cluster randomised controlled trial to \\
\hline & $\begin{array}{l}\text { Anderson, } \\
\text { Simpson, N }\end{array}$ & & \\
\hline & $\begin{array}{l}\text { Wong, N., Kady, L., } \\
\text { Mewton, } \\
\text { Sunderland, M., } \quad \text { \& } \\
\text { Andrews, G. }\end{array}$ & $\underline{2014}$ & $\begin{array}{l}\text { Preventing anxiety and depression in } \\
\text { adolescents: A randomised controlled } \\
\text { trial of two school based Internet- } \\
\text { delivered cognitive behavioural therapy } \\
\text { programmes. }\end{array}$ \\
\hline & $\begin{array}{l}\text { Berle, D., Moulds, M. } \\
\text { L., Starcevic, V., } \\
\text { Milicevic, D., Dale, E., }\end{array}$ & $\underline{2016}$ & $\begin{array}{l}\text { Does emotional reasoning change } \\
\text { during cognitive behavioural therapy } \\
\text { for anxiety? Cognitive Behaviour }\end{array}$ \\
\hline & $\begin{array}{l}\text { Viswasam, } \\
\text { Brakoulias, V. }\end{array}$ & & Therapy \\
\hline & Esbjørn, B. H & $\underline{2016}$ & $\begin{array}{l}\text { Can Parents Treat their Anxious } \\
\text { Child using CBT? A Brief Report of a } \\
\text { Self-Help Program. }\end{array}$ \\
\hline & $\begin{array}{l}\text { Mcleod, B. D., Islam, } \\
\text { N. Y., Chiu, A. W., }\end{array}$ & $\underline{2014}$ & $\begin{array}{l}\text { The Relationship Between Alliance } \\
\text { and Client Involvement in CBT for }\end{array}$ \\
\hline & Smith, M. M., Chu, B. & & Child Anxiety Disorders The \\
\hline & $\begin{array}{l}\text { C., Wood, J. J., Smith, } \\
\text { M. M., \& Wood, J. J. }\end{array}$ & & $\begin{array}{l}\text { Relationship Between Alliance and } \\
\text { Client Involvement in CBT for Child } \\
\text { Anxiety Disorders. }\end{array}$ \\
\hline & $\begin{array}{l}\text { Ilkhchi, S., Poursharifi, } \\
\text { H., \& Alilo, M. }\end{array}$ & $\underline{2014}$ & $\begin{array}{l}\text { The effectiveness of Cognitive- } \\
\text { Behavioral Group Therapy on self- } \\
\text { efficacy and assertiveness among } \\
\text { anxious female students of high } \\
\text { schools }\end{array}$ \\
\hline \multirow{5}{*}{$\begin{array}{l}\text { CBT and } \\
\text { Students } \\
\text { Emotion }\end{array}$} & Fernández-martínez, & $\underline{2019}$ & One-Year follow-up effects of a \\
\hline & I., Orgilés, $\quad$ M., & & cognitive behavior therapy-based \\
\hline & $\begin{array}{l}\text { Morales, A., Espada, } \\
\text { J. P., \& Essau, C. A. }\end{array}$ & & $\begin{array}{l}\text { transdiagnostic program for } \\
\text { emotional problems in young } \\
\text { children: A school-based cluster- } \\
\text { randomized controlled trial. }\end{array}$ \\
\hline & Lars Goran Ost, E. S & 2013 & $\begin{array}{l}\text { Cognitive Behaviour Therapy for } \\
\text { Dental Phobia and Anxiety. In } \\
\text { Cognitive Behaviour Therapy for } \\
\text { Dental Phobia and Anxiety. }\end{array}$ \\
\hline & $\begin{array}{l}\text { Essau, C. A., } \\
\text { Sasagawa, S., Jones, } \\
\text { G., Fernandes, B., \& } \\
\text { Ollendick, T. H. }\end{array}$ & 2019 & $\begin{array}{l}\text { Evaluating the real-world } \\
\text { effectiveness of a cognitive behavior } \\
\text { therapy- based transdiagnostic } \\
\text { program for emotional problems in } \\
\text { children in a regular school setting }\end{array}$ \\
\hline \multirow{3}{*}{$\begin{array}{l}\text { CBT and } \\
\text { Students Self } \\
\text { Confidence, } \\
\text { Self Efficacy }\end{array}$} & Harding, L. & 2017 & Building positive thinking habits: \\
\hline & & & $\begin{array}{l}\text { increasing self-confidence \& } \\
\text { resilience in young people through } \\
\text { CBT }\end{array}$ \\
\hline & Ali Khaneh Keshi, B & $\underline{2013}$ & $\begin{array}{l}\text { Effectiveness of Cognitive Behavior } \\
\text { Therapy on Self-Efficacy Among } \\
\text { High School Students }\end{array}$ \\
\hline
\end{tabular}


Biblio Couns : Jurnal Kajian Konseling dan Pendidikan | Vol. 3 No. 1 Maret 2020

\begin{tabular}{|c|c|c|c|}
\hline & $\begin{array}{l}\text { Rosmawati Mohamad } \\
\text { Rasit, S. Z. C. A. R. }\end{array}$ & 2017 & $\begin{array}{l}\text { The Role of Self Efficacy and } \\
\text { Cognitive Behaviour Therapy in } \\
\text { Forming Posocial Behaviour. }\end{array}$ \\
\hline \multirow[t]{2}{*}{$\begin{array}{l}\text { CBT and } \\
\text { Local } \\
\text { Wisdom }\end{array}$} & Hidayah, N & 2017 & $\begin{array}{l}\text { Need of Cognitive-Behavior } \\
\text { Counseling Model Based on Local } \\
\text { Wisdom to Improve Meaning of Life } \\
\text { of Madurese Culture Junior High } \\
\text { School Students. }\end{array}$ \\
\hline & $\begin{array}{l}\text { Hidayah, N., \& Hanafi, } \\
\text { H. }\end{array}$ & $\underline{2017}$ & $\begin{array}{l}\text { Urgency cognitive-behavioral } \\
\text { counseling based on local wisdom } \\
\text { for junior high school counselor in } \\
\text { East Java }\end{array}$ \\
\hline
\end{tabular}

Berdasarkan studi yang berbeda, banyak metode yang digunakan untuk mengurangi kecemasan siswa. Dalam studi ini, metode kognitif lebih bermanfaat daripada metode perilaku untuk perawatan kecemasan (Mckay, 2019). Jadi dalam dua dekade ini, ada lebih banyak penekanan pada metode kognitif dan intervensi kognitif-perilaku dalam pengobatan kecemasan(Lotfi et al., 2011; Vincent et al., 2018), hasil penelitian lainnya yang menggembirakan dan menunjukkan bahwa program pencegahan kecemasan yang diberikan di sekolah kepada anak-anak berusia 9-10 tahun memang mengurangi gejala kecemasan pada 12 bulan. Temuan bahwa anak-anak dengan gejala rendah yang diuntungkan dari program mendukung pendekatan universal, yang juga cocok dengan jadwal sekolah dan struktur organisasi. Namun, data kami menunjukkan bahwa program yang sama dapat menghasilkan efek yang berbeda tergantung pada siapa memberikannya (Stallard et al., 2014). siswa dalam kelompok intervensi depresi menunjukkan peningkatan signifikan dalam kecemasan dan gejala depresi pada akhir kursus CBT, sementara siswa dalam intervensi kecemasan menunjukkan pengurangan gejala kecemasan setelah diberikan pengobatan CBT (Wong et al., 2014).

Mungkin ada variasi dalam bagaimana CBT diberikan antara terapis dan banyak peserta membutuhkan lebih dari 12 sesi terapi, sehingga penilaian "posttreatment" mungkin telah terjadi sebelum perolehan tambahan yang dibuat (Rohde et al., 2014). Penalaran emosional adalah proses yang membutuhkan waktu lebih lama untuk berubah daripada proses dan bias kognitif lainnya. Akhirnya, sampel terdiri dari kelompok individu yang heterogen dengan gangguan kecemasan dan tetap ada kemungkinan bahwa ada perbedaan dalam penalaran emosional antara kelompok gangguan yang berbeda. Misalnya, penalaran emosional mungkin banyak berubah selama pengobatan untuk gangguan panik primer, tetapi relatif sedikit untuk pengobatan gangguan kecemasan social (Berle et al., 2016; Esbjørn, 2016).

Kemanjuran yang lebih tinggi dari CBT multi-sesi dibandingkan sesi tunggal atau intervensi singkat lainnya, dan tingkat drop out yang lebih rendah dibandingkan dengan kondisi control. Namun, ukuran efek CBT lebih kecil jika dibandingkan dengan intervensi psikososial lainnya (misalnya manajemen kontingensi, pencegahan kambuh, dan pendekatan motivasi) untuk ketergantungan zat, dan perawatan agonis menunjukkan ukuran efek yang lebih besar pada penggunaan CBT terhadap ketergantungan obat tertentu, seperti opioid dan ketergantungan alkohol.

Beberapa penelitian menyarankan bahwa aliansi dan keterlibatan klien memainkan peran kunci dalam CBT untuk kecemasan anak, meskipun beberapa penelitian telah meneliti masalah ini. Oleh karena itu kami memeriksa hubungan antara aliansi dan keterlibatan klien selama CBT untuk kecemasan anak untuk lebih memahami bagaimana proses terapi ini berhubungan satu sama lain selama pengobatan. Penelitian kami unik karena kami menggunakan ukuran yang kuat secara psikometrik untuk menilai setiap proses terapi, mengukur setiap proses terapi pada dua titik waktu selama perawatan, dan menggunakan tim independen untuk mengkode setiap proses terapi. Seperti yang dihipotesiskan, perubahan positif dalam aliansi diprediksi keterlibatan yang lebih tinggi dalam pengobatan. Namun, kami juga menemukan bahwa perubahan keterlibatan yang positif memprediksi aliansi yang lebih kuat di kemudian hari dalam pengobatan. Bersama- 
sama, temuan ini menunjukkan hubungan antara aliansi dan keterlibatan klien dalam CBT untuk kecemasan anak mungkin lebih kompleks daripada hipotesis sebelumnya.(Mcleod et al., 2013)

Penelitian Vosoughi menunjukkan bahwa para peserta mengalami penurunan kecemasan yang signifikan, dan peningkatan self-efficacy dan ketegasan dalam memnentukan keputusan. Temuan penelitian ini menunjukkan bahwa CBT dapat meningkatkan efikasi diri dan ketetapan penentuan keputusan di antara siswa sekolah menengah yang mengalami gangguan kecemasan (Vosoughi et al., 2014).

Penelitian pertama ini untuk menguji efektivitas jangka panjang CBT dalam sampel yang ditunjukkan anak-anak muda berbahasa Spanyol. Sejalan dengan hipotesis tersebut, anak-anak yang berpartisipasi dalam kasus ini menunjukkan penurunan yang kecil, tetapi signifikan secara statistik dari penurunan kecemasan dan gejala depresi setelah intervensi. Hasil penelitian menyarankan efek jangka panjangnya, karena hasil efek pasca intervensi langsung menunjukkan dampak yang signifikan pada hasil yang sama(Fernández-martínez et al., 2019). Hasil temuan dari penulis lain yang ditunjukkan bahwa studi pencegahan RCT (Randomized Controlled Trial) menggunakan program berbasis CBT lain yang menargetkan anak yang lebih tua berusia 8-13 tahun menunjukkan bahwa pengurangan kecemasan dan gejala depresi dipertahankan hingga 1 tahun setelah intervensi. Namun, efek dari CBT lebih besar dalam post tes dibandingkan dengan tindak lanjut, berdasarkan ukuran pengaruh dari perbedaan yang signifikan secara statistik. Hasil pada keluar utama datang dari penelitian ini sejalan dengan studi analitik dari kecemasan pencegahan dan / atau intervensi depresi pada anak-anak, menunjukkan efek yang kecil namun sangat signifikan, pada gejala-gejala yang lebih luas dalam tindak lanjut. Keuntungan tambahan yang ditemukan pada tindak lanjut yang terjadi 12 bulan terkait dengan gejala panik / agorafobia. Secara khusus, dalam 12 bulan tindak lanjut, kemungkinan timbulnya kepanikan / agorafobi pada kelompok ini adalah $21 \%$ lebih rendah daripada dalam kelompok treatmen lainnya (Lars Goran Ost, 2013).

Hasil Penelitian lain adalah terdapat kesepakatan antara laporan diri, orang tua, dan guru, menunjukkan penurunan signifikan dari gejala emosional dari pretest ke posttest dan pretest untuk tindak lanjut. Efek utama dari gender adalah signifikan untuk gejala kecemasan, gejala emosional masalah teman sebaya, dan perilaku prososial. Analisis video dari yang terekam dalam 2 menit awal menunjukkan peningkatan yang signifikan dalam panjang pandangan mata, kualitas vokal, panjang bicara, manifestasi kenyamanan, dan aliran percakapan. Namun, peningkatan harga diri yang dihipotesiskan tidak menjadi mediator perubahan gejala sebelum atau sesudah kecemasan atau skor subskala fobia social (Essau et al., 2019).

Hasil CBT dan Percaya Diri menemukan berbagai pendekatan dan teknik kombinasi yang menarik, disampaikan dengan cara yang terstruktur dan ramah-praktisi yang memerlukan persiapan terbatas, terutama karena ada CD Rom pendukung dengan semua lembar kerja dan sumber daya yang diperlukan untuk menjalankan kelompok. Banyak intervensi lain yang tersedia untuk sekolah dan EP sering datang dari satu pendekatan tertentu atau yang lain, tetapi ini adalah kombinasi kreatif dari pendekatan berbasis bukti (Harding, 2017). Namun, meskipun sumber daya ini didasarkan pada pendekatan berbasis bukti, itu tidak termasuk informasi tentang bagaimana intervensi khusus ini dalam praktiknya. Akan berguna untuk memiliki informasi lebih lanjut tentang keefektifan kumpulan pendekatan khusus ini, agar EP merasa percaya diri dalam merekomendasikannya ke sekolah-sekolah daripada pendekatan lain.

Penelitian lain tentang CBT dan Self Efficacy juga dijelaskan dalam penelitian Ali yang menunjukkan hasil Penelitian ini telah dilakukan untuk menyelidiki efektivitas terapi perilaku kognitif (CBT) pada self-efficacy di kalangan siswa sekolah menengah. Dalam penelitian ini hipotesis berikut diverifikasi dengan metode statistik yang sesuai: CBT efektif dalam meningkatkan self-efficacy (Ali Khaneh Keshi, 2013). Self-efficacy adalah konstruk yang terkait dengan strategi CBT yang mungkin terlibat dalam mengubah pikiran, perilaku, emosi, dan kinerja individu. 
Cognitive behavioral therapy (CBT) adalah ekspresi universal yang berasal dari model kognitif gangguan afektif, yang terdiri dari banyak pendekatan yang didasarkan pada postulat bahwa kognisi secara signifikan mempengaruhi emosi dan hambatan perilaku, dan juga menawarkan berbagai kognitif berbasis bukti dan teknik dan terapi perilaku. Konsep self-efficacy menjelaskan sikap individu yang percaya pada diri mereka sendiri. Ini menjadi katalis untuk proses kognitif rasional dalam membentuk perilaku individu(Rosmawati Mohamad Rasit, 2017).

Cognitive behavior counseling bisa dikoloborasikan dengan local wisdom yang ada di masyarakat untuk bisa digunakan sebagai pendekatan model yang bisa membantu siswa di sekolah. Penelitian tentang CBT dan local Wisdon telah dikaukan oleh Nur Hidayah dengan hasil Terkait dengan model konseling berbasis etnis memiliki nilai strategis untuk (1) membangun pencitraan layanan konseling internal oleh profesi konselor dan lainnya seperti psikolog, psikoterapis, adalah layanan profesional berdasarkan kearifan lokal; (2) memfasilitasi konselor sambil melayani konseli budaya yang beragam menggunakan teknik konversi yang sesuai sesuai dengan nilai-nilai budaya konseli. Selain itu konselor diharapkan benar-benar menumbuhkan penyelesaian masalah dengan tepat. Pada gilirannya, konselor senang ketika memberikan layanan konseling; (3) Konseling Kognitif-Perilaku berdasarkan kearifan lokal menjadi paradigma konseling baru di Indonesia khususnya di Jawa Timur; (Hidayah \& Hanafi, 2017) dan (4) menyebarluaskan pentingnya layanan Konseling Perilaku Cognitive berdasarkan kearifan lokal bagi siswa, sehingga persiapan sumber daya manusia masa depan bangsa kita meningkatkan kualitasnya.

Hasil penelitian lainnya adalah penelitian survei tentang kebutuhan konselor terhadap model Konseling Perilaku Kognitif berdasarkan kearifan lokal budaya Madura menunjukkan bahwa ada sambutan dan dukungan dan persyaratan yang sangat tinggi untuk pengembangan model Konseling Kognitif-Perilaku berdasarkan budaya Madura. Penampilan model Kognitif-Perilaku Konseling berdasarkan kearifan lokal budaya Madura dilengkapi dengan panduan konseling untuk konselor. Berdasarkan hasil penelitian usulan saran untuk bimbingan dan konseling praksis untuk memanfaatkan hasil pengembangan model konseling berbasis kearifan lokal, khususnya budaya Madura untuk meningkatkan makna kehidupan siswa sekolah menengah pertama. Model konseling berdasarkan kearifan lokal lainnya perlu dikembangkan secara lebih luas di Jawa Timur, seperti budaya Osing, Bawean, dan Materaman (Hidayah \& Ramli, 2017).

\section{KESIMPULAN}

Ulasan dalam artikel ini adalah tentang studi meta-analitik yang memeriksa keefektivitasan CBT menunjukkan bahwa pengobatan ini telah digunakan untuk berbagai masalah psikologis di sekolah. Secara umum, basis bukti CBT sangat kuat, dan terutama untuk mengobati gangguan kecemasan. Namun, terlepas dari basis literatur yang sangat besar, masih ada kebutuhan yang jelas untuk penelitian berkualitas tinggi yang memeriksa kemanjuran CBT. Selain itu, kemanjuran CBT dipertanyakan untuk beberapa masalah, yang menunjukkan bahwa perbaikan lebih lanjut dalam strategi CBT masih diperlukan. Selain itu, banyak studi meta-analitik termasuk studi dengan ukuran sampel kecil atau kelompok kontrol yang tidak memadai. Selain itu, kecuali untuk anak-anak dan populasi lansia, tidak ada studi meta-analitik CBT yang dilaporkan pada subkelompok tertentu, seperti etnis minoritas dan sampel berpenghasilan rendah.

\section{REFERENSI}

Ali Khaneh Keshi, B. (2013). Effectiveness of Cognitive Behavior Therapy on Self-Efficacy Among High School Students. Asian Journal Of Management Science and Education, 2(4), 68-79. 
Alladin, Assen. (2015). Integrative CBT for Disorders. In John Wiley (Ed.), Wiley Blackdell (First Edit). John Wiley \& Sons, Ltd.

Anastopoulos, A. D., \& King, K. A. (2015). A Cognitive-Behavior Therapy and Mentoring Program for College Students With ADHD. Cognitive and Behavioral Practice, 22(2), 141-151. https://doi.org/10.1016/i.cbpra.2014.01.002

Asbrand, J., Heinrichs, N., Nitschke, K., Wolf, O. T., \& Tuschen-ca, B. (2019). Psychoneuroendocrinology Repeated stress leads to enhanced cortisol stress response in child social anxiety disorder but this e ff ect can be prevented with CBT. 109(June). https://doi.org/10.1016/j.psyneuen.2019.06.003

Asbrand, J., Heinrichs, N., Nitschke, K., Wolf, O. T., Schmidtendorf, S., \& Tuschen-Caffier, B. (2019). Repeated stress leads to enhanced cortisol stress response in child social anxiety disorder but this effect can be prevented with CBT. Psychoneuroendocrinology, 109 (January). https://doi.org/10.1016/i.psyneuen.2019.06.003

Berle, D., Moulds, M. L., Starcevic, V., Milicevic, D., Dale, E., Viswasam, K., Brakoulias, V., Berle, D., Moulds, M. L., Starcevic, V., Milicevic, D., Dale, E., Viswasam, K., \& Brakoulias, V. (2016). Does emotional reasoning change during cognitive behavioural therapy for anxiety? Cognitive Behaviour Therapy ISSN:, 37(1). https://doi.org/10.1080/16506073.2015.1115892

Castella, K. De, Goldin, P., Jazaieri, H., Heimberg, G., Dweck, C. S., \& Gross, J. J. (2014). Emotion Beliefs and Cognitive Behavioural Therapy for Social Anxiety Disorder. January 2015, 37-41. https://doi.org/10.1080/16506073.2014.974665

Cully, J. A., \& Teten, A. L. (2008). Therapists_Guide_To_Brief_Cbtmanual. https://depts.washington.edu/dbpeds/therapists guide to brief cbtmanual.pdf

Eiraldi, R., Mautone, J. A., Khanna, M. S., Power, T. J., Orapallo, A., Cacia, J., Schwartz, B. S., McCurdy, B., Keiffer, J., Paidipati, C., Kanine, R., Abraham, M., Tulio, S., Swift, L., Bressler, S. N., Cabello, B., \& Jawad, A. F. (2018). Group CBT for Externalizing Disorders in Urban Schools: Effect of Training Strategy on Treatment Fidelity and Child Outcomes. Behavior Therapy, 49(4), 538-550. https://doi.org/10.1016/j.beth.2018.01.001

Esbjorn, B. H. (2016). Can Parents Treat their Anxious Child using CBT? A Brief Report of a Self-Help Program. Acta Psychopathologica, 02(01), 1-5. https://doi.org/10.4172/2469-6676.100036

Essau, C. A., Sasagawa, S., Jones, G., Fernandes, B., \& Ollendick, T. H. (2019). Evaluating the real-world effectiveness of a cognitive behavior therapy- based transdiagnostic program for emotional problems in children in a regular school setting. Journal of Affective Disorders, 253(April), 357-365. https://doi.org/10.1016/j.jad.2019.04.036

Fernández-martínez, I., Orgilés, M., Morales, A., Espada, J. P., \& Essau, C. A. (2019). OneYear follow-up effects of a cognitive behavior therapy-based transdiagnostic program for emotional problems in young children: A school-based cluster-randomized controlled trial. Journal of Affective Disorders, October, 1-9. https://doi.org/10.1016/.j.jad.2019.11.002 
Fitzgerald, S. (Clinical psychologist). (2013). CBT workbook For Dummies. John Wiley \& Sons, Ltd.

Freeman, A. (2006). Encyclopedia of cognitive behavior therapy. In Choice Reviews Online (Vol. 43, Issue 07). https://doi.org/10.5860/choice.43-3763

Harding, L. (2017). Building positive thinking habits: increasing self-confidence \& resilience in young people through CBT. Educational Psychology in Practice, 33(3), 335-336. https://doi.org/10.1080/02667363.2017.1295603

Hidayah, N., \& Hanafi, H. (2017). Urgency cognitive-behavioral counseling based on local wisdom for junior high school counselor in East Java. Advances in Social Science, Education and Humanities Research, 118(May 2019). https://doi.org/10.2991/icset$\underline{17.2017 .149}$

Hidayah, N., \& Ramli, M. (2017). Need of Cognitive-Behavior Counseling Model Based on Local Wisdom to Improve Meaning of Life of Madurese Culture Junior High School Students. Advances in Social Science, Education and Humanities Research, 128(Icet), 301-307. https://doi.org/10.2991/icet-17.2017.53

Ilkhchi, S., Poursharifi, H., \& Alilo, M. (2011). The Effectiveness of Cognitive-Behavioral Group Therapy on Self-Efficacy and Assertiveness Among Anxious Female Students of High Schools. Procedia - Social and Behavioral Sciences, 30, 2586-2591. https://doi.org/10.1016/j.sbspro.2011.10.506

Jongerden, L., \& Bögels, S. M. (2015). Parenting, Family Functioning and Anxiety-Disordered Children: Comparisons to Controls, Changes After Family Versus Child CBT. Journal of Child and Family Studies, 24(7), 2046-2059. https://doi.org/10.1007/s10826-014$\underline{0005-6}$

Lars Goran Ost, E. S. (2013). Cognitive Behaviour Therapy for Dental Phobia and Anxiety. In Cognitive Behaviour Therapy for Dental Phobia and Anxiety. https://doi.org/10.1002/9781118499825

Lotfi, S., Eizadi-fard, R., Ayazi, M., \& Amin, M. (2011). Social and The Effect of Meichenbaum 's Cognitive Behaviour Modification Therapy on Reduction of Test Anxiety Symptoms in High School Girls. Procedia Social and Behavioral Sciences, 00, 835-838. https://doi.org/10.1016/i.sbspro.2011.10.162

Maric, M., van Steensel, F. J. A., \& Bögels, S. M. (2018). Parental Involvement in CBT for Anxiety-Disordered Youth Revisited: Family CBT Outperforms Child CBT in the Long Term for Children With Comorbid ADHD Symptoms. Journal of Attention Disorders, 22(5), 506-514. https://doi.org/10.1177/1087054715573991

Mckay, D. (2019). ScienceDirect Introduction to the Special Issue : Mechanisms of Action in Cognitive-Behavior Therapy. Behavior Therapy, xxxx, 6-8. https://doi.org/10.1016/j.beth.2019.07.006

Mcleod, B. D., Islam, N. Y., Chiu, A. W., Smith, M. M., Chu, B. C., Wood, J. J., Smith, M. M., \& Wood, J. J. (2013). The Relationship Between Alliance and Client Involvement in CBT for Child Anxiety Disorders The Relationship Between Alliance and Client Involvement in CBT for Child Anxiety Disorders. Journal of Clinical Child \& Adolescent Psychology, October 2014, 37-41. https://doi.org/10.1080/15374416.2013.850699 
Neill, E. L., Weems, C. F., Scheeringa, M. S., Neill, E. L., Weems, C. F., Scheeringa, M. S., Neill, E. L., \& Weems, C. F. (2017). CBT for Child PTSD is Associated with Reductions in Maternal Depression: Evidence for Bidirectional Effects CBT for Child PTSD is Associated with Reductions in Maternal Depression: Evidence for Bidirectional Effects. Journal of Clinical Child \& Adolescent Psychology, 00(00), 1-11. https://doi.org/10.1080/15374416.2016.1212359

Nosouhian, H., \& Javadi, F. (2018). The comparison between self-confidence and symptoms of aggression and hyperactivity (ADHD) in children. Early Child Development and Care, 188(6), 723-730. https://doi.org/10.1080/03004430.2016.1230608

Passiatore, Y., Pirchio, S., Oliva, C., Panno, A., \& Carrus, G. (2019). Self-efficacy and anxiety in learning English as a Foreign language: Singing in class helps speaking performance. Journal of Educational, Cultural and Psychological Studies, 2019(20), 121-138. https://doi.org/10.7358/ecps-2019-020-passi

Raedt, R. De. (2020). Contributions from neuroscience to the practice of Cognitive Behaviour Therapy: Translational psychological science in service of good practice. Behaviour Research and Therapy, 103545. https://doi.org/10.1016/j.brat.2019.103545

Rohde, P., Stice, E., Shaw, H., \& Gau, J. M. (2014). Behaviour Research and Therapy Cognitive-behavioral group depression prevention compared to bibliotherapy and brochure control: Nonsigni fi cant effects in pilot effectiveness trial with college students. Behaviour Research and Therapy, 55, 48-53. https://doi.org/10.1016/i.brat.2014.02.003

Rosmawati Mohamad Rasit, S. Z. C. A. R. (2017). The Role of Self Efficacy and Cognitive Behaviour Therapy in Forming Posocial Behaviour. Cognitive Bahviour Therapy, 5(1). https://doi.org/10.5772/intechopen.81957

Salomonsson, S., Santoft, F., Lindsäter, E., Ejeby, K., Öst, L., Lekander, M., Ljótsson, B., \& Hedman-, E. (2019). Predictors of outcome in guided self-help cognitive behavioural therapy for common mental disorders in primary care. Cognitive Behaviour Therapy, 00(00), 1-20. https://doi.org/10.1080/16506073.2019.1669701

Samhsa, Somers, J., Queree, M., Broderick, J., Leung, B., Cully, J. A., Teten, A. L., \& Anxiety BC. (2006). WHAT IS CBT ? What to Expect if You See a CBT Therapist. Department of Veterans Affairs South Central MIRECC, March, 117.

Stallard, P., Skryabina, E., Taylor, G., Phillips, R., Daniels, H., Anderson, R., \& Simpson, N. (2014). Classroom-based cognitive behaviour therapy ( FRIENDS ): a cluster randomised controlled trial to Prevent Anxiety in Children through Education in Schools ( PACES ). The Lancet Psychiatry, 1(3), 185-192. https://doi.org/10.1016/S2215$\underline{0366(14) 70244-5}$

Taylor, D. J., Zimmerman, M. R., Gardner, C. E., Williams, J. M., Grieser, E. A., Tatum, J. I., Bramoweth, A. D., Francetich, J. M., \& Ruggero, C. (2014). A pilot randomized controlled trial of the effects of cognitive-behavioral therapy for insomnia on sleep and daytime functioning in college students. Behavior Therapy, 45(3), 376-389. https://doi.org/10.1016/i.beth.2013.12.010

Vincent, L., Norton, P. J., \& Norton, P. J. (2018). Predictors and consequences of sudden gains in transdiagnostic cognitive-behavioural therapy for anxiety disorders. Cognitive Behaviour Therapy, 00(00), 1-20. https://doi.org/10.1080/16506073.2018.1513557 
Vosoughi, S., Poursharifi, H., \& Mahmood, M. (2014). Procedia Social and The effectiveness of Cognitive-Behavioral Group Therapy on self- efficacy and assertiveness among anxious female students of high schools. Procedia Social and Behavioral Sciences, 21(1), 2586-2591. https://doi.org/10.1016/i.sbspro.2011.10.506

Wong, N., Kady, L., Mewton, L., Sunderland, M., \& Andrews, G. (2014). Preventing anxiety and depression in adolescents: A randomised controlled trial of two school based Internet-delivered cognitive behavioural therapy programmes. Internet Interventions, 1(2), 90-94. https://doi.org/10.1016/j.invent.2014.05.004 